\section{Obstructive sleep apnoea due to a dermoid cyst of the floor of the mouth}

\author{
J M Goldman, D J Barnes, D V Pohl
}

\begin{abstract}
A case of obstructive sleep apnoea is reported that was caused by a dermoid cyst of the floor of the mouth and cured by surgery.
\end{abstract}

Although abnormalities of the upper airway are known to be capable of causing obstructive sleep apnoea, a dermoid cyst has not to our knowledge been reported as a cause.

\section{Case report}

A 38 year old woman presented with a one year history of chronic tiredness. Her husband had noted snoring and episodes of apnoea, and she described symptoms of excessive daytime sleepiness. On examination she looked well and weighed $49 \mathrm{~kg}$. The only abnormal finding was an opaque soft tissue mass seen under the tongue (figure). Computed tomography of the upper airway showed a cystic mass beneath the tongue and narrowing of the nasopharynx (at the level of the uvula) and oropharynx. Nasopharyngoscopy confirmed the presence of airway occlusion at these sites due to posterior displacement of the tongue by the lesion.

Nocturnal polysomnography recorded 40 episodes of oxygen desaturation an hour due to upper airway obstruction; the minimum

oxyhaemoglobin saturation $\left(\mathrm{SaO}_{2}\right)$ reached was $88 \%$. A diagnosis of obstructive sleep apnoea of moderate severity was made. The patient proceeded to surgery and a midline cyst of the floor of the mouth was removed. This measured $40 \times 35 \times 25 \mathrm{~mm}$ and contained yellow pultaceous material. Histological examination showed it to be lined with keratinising squamous epithelium and chronic inflammatory granulation tissue. A diagnosis of a dermoid cyst was made. A repeat sleep study after surgery gave normal results. The patient subsequently made a complete recovery and is now symptom free.

\title{
Discussion
}

Midline sublingual dermoid cysts arise from epithelial rests that are left as the two contributions to the tongue from the back of the mandibular arch merge together. ${ }^{1}$ They are usually lined by stratified squamous epithelium with or without dermal appendages and are filled with keratin. Such cysts are known to enlarge backwards between the genial muscles into the tongue and down towards the hyoid, impinging on the upper airway.

Obstructive sleep apnoea is a common disorder affecting $1-4 \%$ of the adult population. It presents as cyclical upper airway obstruction during sleep with associated falls in arterial oxygen saturation and arousal. ${ }^{2}$ Possible long term sequelae include hypertension, stroke, and cardiorespiratory failure. It may be caused by localised abnormalities of the upper airway, including tonsillar hypertrophy, ${ }^{34}$ tonsillar lymphoma, ${ }^{5}$ oropharyngeal papillomatosis, ${ }^{6}$ micrognathia, ${ }^{7}$ retrognathia, and lymphocytic lymphoma of the submaxillary and sublingual salivary glands. ${ }^{9} \mathrm{We}$ could find no previous description of sleep apnoea due to a dermoid cyst. It is important that such lesions are recognised as they can be cured by surgery.

D J Barnes

Address for correspondence Dr J M Goldman, Lung Function Unit, Killingbeck

Accepted 26 October 1989

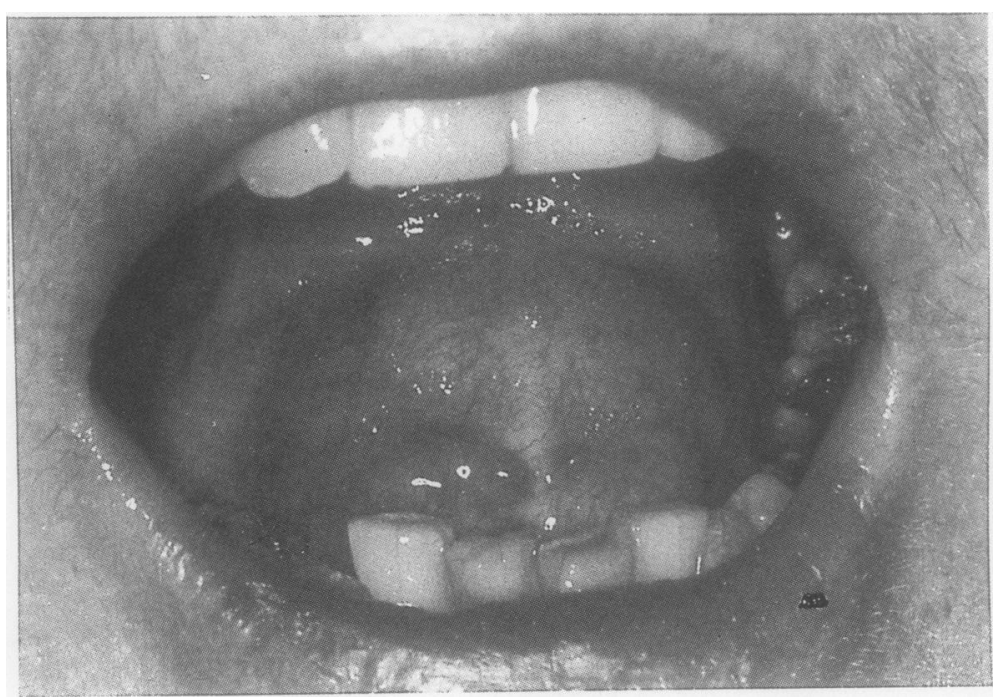

1 Harding Rains AJ, Mann CV, eds. Bailey and Loves' short textbook of surgery. 18th ed. London: HK Lewis, 1988:567.

2 Sullivan CE, Issa FG. Obstructive sleep apnea. Clin Chest Med 1985;6:633-50.

3 Orr WC, Martin RJ. Obstructive sleep apnea associated with tonsillar hypertrophy in adults. Arch Intern Med tonsillar hyper

4 Mangat D, Orr WC, Smith RD. Sleep apnea hypersomnolence and upper airway obstruction secondary to somnolence and upper airway obstruction secondary to adenotonsillar

5 King M, Gleeson M, Rees J. Obstructive sleep apnoea and tonsillar lymphoma. Br Med J 1987;294:1604-5.

6 Brodsky L, Siddique SY, Stanievich JF. Massive oropharyngeal papullomatosis causing obstructive sleep apnea in a child. Arch Otolaryngol Head Neck Surg 1987;113:882-4.

7 Coccagna G, Cirignotta F, Lugaresi E. The bird-like face syndrome (acquired micrognathia hypersomnia) and sleep apnea. In: Guilleminault C, Dement WC, eds. The sleep apnea syndromes. New York, Liss, 1978:259-72.

8 Innes NK, Orr WC, Smith RO, et al. Retrognathia and sleep apnea: a life threatening condition masquerading as narapnea: a life threatening condition

9 Zorick F, Roth T, Kramer M, Flessa H. Exacerbation of upper airway sleep apnea by lymphocytic lymphoma. Chest 1980;77:689-90. 